\title{
A Preliminary Study on the Thermal Performance of a Ventilated Honey Cassette for Stingless Bees
}

\author{
Firdaus Basrawi ${ }^{1,}$, A Rahman A Hamid ${ }^{2}$, Rizduan Bahari ${ }^{2}$, Mohd Najib Mohd Noordin \\ ${ }^{3}$, and Mohd Hazwan Yusof ${ }^{1}$ \\ ${ }^{1}$ Meliponini Engineering Laboratory (MepEL), Energy Sustainability Focus Group (ESFG), Faculty \\ of Mechanical Engineering, Universiti Malaysia Pahang \\ ${ }^{2}$ Qlulut Global, NO.48 Lrg 5 Taman Kampong, Padang Damai, Tanjung Pasir, Jalan Bk Goh,25200 \\ Kuantan, Pahang \\ ${ }^{3}$ RISDA, Kuala Kangsar District 33000 Kuala Kangsar, Perak
}

\begin{abstract}
Stingless bees are very sensitive to the changes of surrounding temperature. A report stated that fertility rate in broodcell is $0 \%$ when the broodcell temperature is higher than $34^{\circ} \mathrm{C}$ or lower than $26^{\circ} \mathrm{C}$. In addition, propolis made honey pot in a honey cassette also could melt when temperature is high. Therefore, the objective of this research is to investigate the temperature profile of a ventilated honey cassette exposed to outdoor conditions, and to evaluate the temperature regulation in the hive using the ventilated honey cassette. To achieve these objectives, two hives with conventional and ventilated honey cassettes were exposed under sun light in cloudy and sunny day. Temperature inside each hive was measured at 3 points and was compared. It was found that there is no significant different between the hives when both hives were exposed under direct sunlight in a cloudy day. However, two significant improvements were found for ventilated hive in sunny day. It could help to reduce temperature at wall of honey cassette consistently below $33^{\circ} \mathrm{C}$. This could avoid the melting of propolis around the ventilated wall area. Furthermore, it could facilitate in better temperature reduction as compared to the conventional honey cassette. However, further study when there is a colony inside the hives must also be conducted to validate the results.
\end{abstract}

\section{Introduction}

Stingless bees predate the stinging honey bee, and was found in the tropical earth for over 65 million years. They have diversify species in tropical and subtropical areas. Diversity of stingless bee, especially in Indo-Malayan region makes classifying them is difficult [1]. Although, stingless bees produce honey as honey bee, produced honey is less, and they do not use water to cool their nest [2]. Temperature of hive for more than $34^{\circ} \mathrm{C}$ causes $0 \%$ fertility rate because of the death of pupae in broodcell [3]. Another study suggested that the

\footnotetext{
*Corresponding author: mfirdausb@ump.edu.my
} 
temperature inside a hive must be around $31-32^{\circ} \mathrm{C}$ for Trigona denoiti [4]. Thus, in natural hives, they live in shaded area inside hole in trees that could provide insulation, and this makes temperature inside the hive is relatively constant [5]. Hence, cooling methods by photovoltaic-thermoelectric and green roof were proposed to prevent overheating of hives when subjected to direct sunlight conditions.

For artificial hives, it is common to have separated compartment for bees to store honey and beebread. This part is usually called as topping or honey cassette. Temperature regulation is also important for this part because, when the temperature is too high, propolis made honey pot could melt and honey cassette will be flooded with honey. Air ventilation for this part is also important because there is activity of fanning the filled honey pot to reduce water content in honey. Therefore, if this space is ventilated, it could help in the honey drying process.

One of the possible cooling and ventilation technique is to provide holes to the honey cassette with wire mesh to avoid treats from other insects. From literature reviewed, there is no study on the ventilated honey cassette, and therefore the objectives of this study are:

- to investigate the temperature profile of the ventilated honey cassette exposed to outdoor conditions, and

- to evaluate the temperature regulation in the hive using ventilated honey cassette.

The study was done by exposing hives with different honey cassettes to outdoor condition. One of the hive was equipped with ventilated honey cassette, another one was equipped with a conventional honey cassette. The temperature profile inside the hives was recorded and analysed to evaluate the feasibility of ventilated honey cassette for stingless bee hives.

\section{Materials and Method}

An experiment was conducted at Universiti Malaysia Pahang, Pekan campus (coordinates: $3.5437^{\circ} \mathrm{N}, 103.4288^{\circ} \mathrm{E}, \mathrm{GMT}+8$ ). Figure 1 shows the overall experimental setup. Two hives were exposed to outdoor conditions without any shades. They have the same broodcell and roof part with identical material, size, and colour. This is to ensure only honey cassettes part is the affecting parameter.

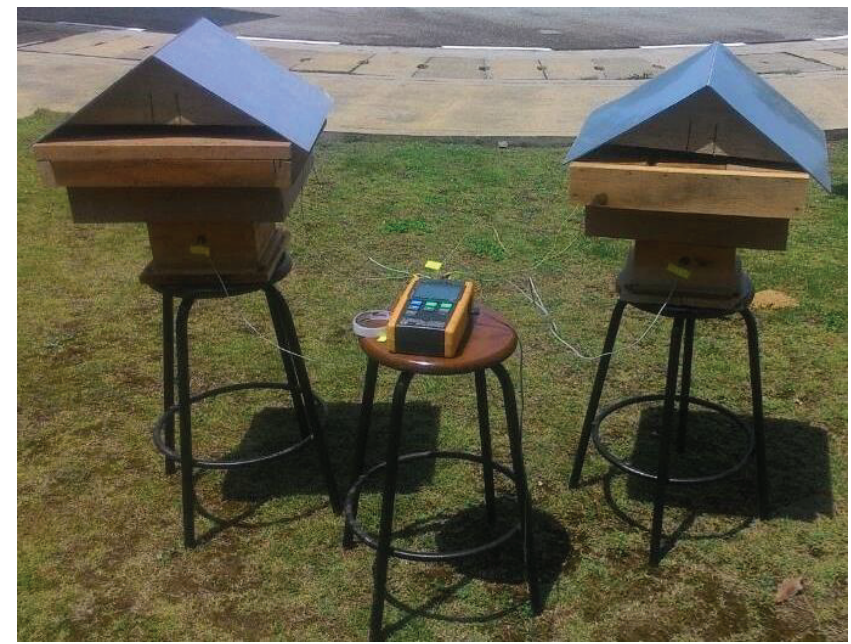

Fig. 1. Overall setup, with thermocouples measuring temperatures inside honey cassette and brood cell compartment of each hives, connected to a temperature data logger. 
One hive was fitted with a ventilated topping as shown in Figure 2, and another one with the conventional one. Both honey cassettes have the same dimensions in terms of inner area. All cracks and gaps were seal with a tape to ensure air could only enters through entrance to simulate the real condition. It should be noted that there is no bees colony inside the hives.

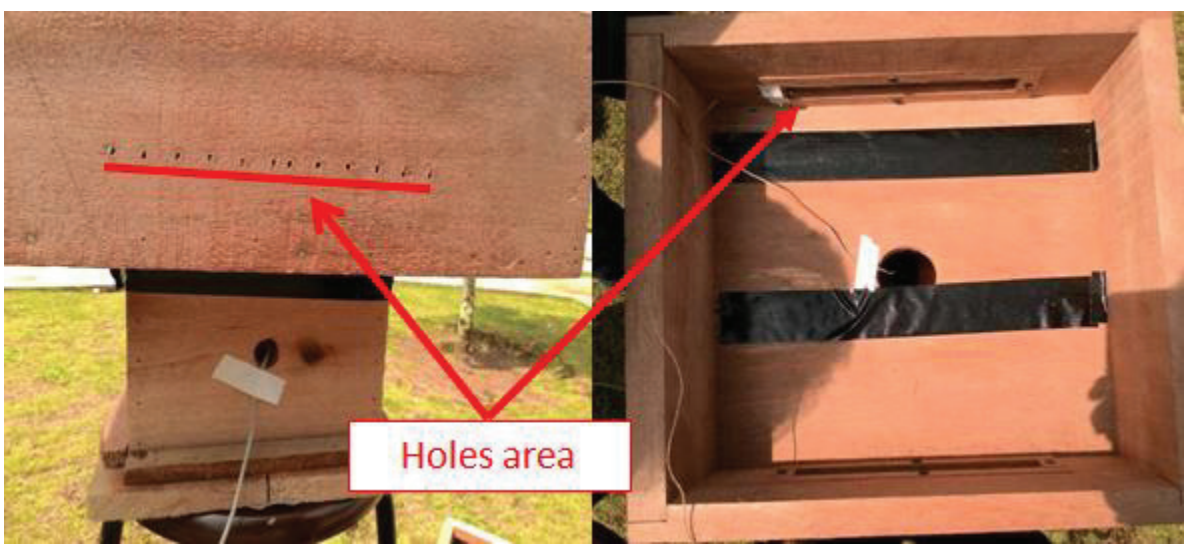

Fig. 2. Hive with ventilated honey cassette.

Temperature were recorded at 3 points for each hive as shown in Figure 3, which are inner wall of both honey cassettes, middle hole of the honey cassette, inside broodcell. The measurement was recorded by a data logger (Lutron BTM-4208SD) shown in Figure 4, which was then transferred into computer for further analysis. K-type thermocouple was used as the sensors.
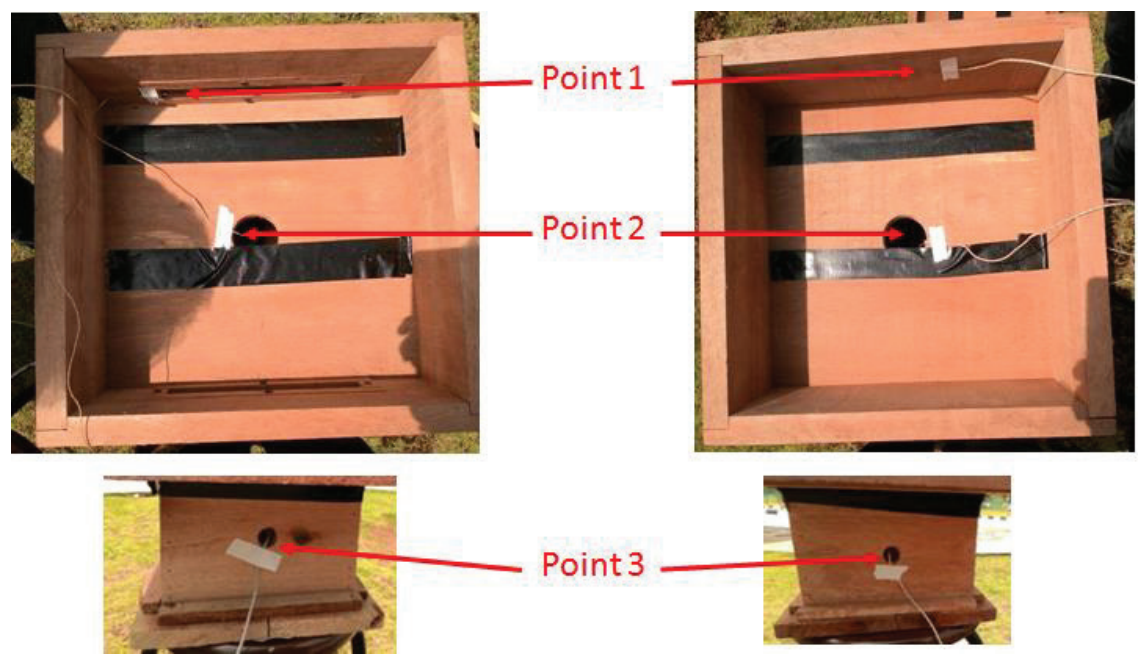

Fig. 3. Temperature recording points. 
Fig. 4. Temperature recorder used.

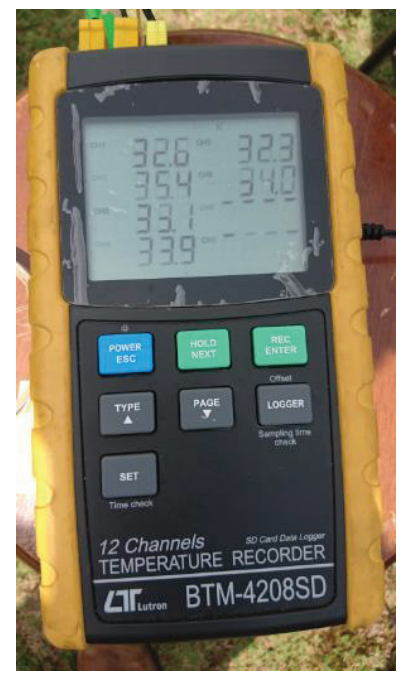

Experiments were conducted 2 times, one time in a sunny day, and one time in a cloudy day. In addition, sampling time was 1 minute. Since this is a preliminary study, environment data including irradiance, humidity, ambient temperature, and wind speed were not recorded.

\section{Results and Discussion}

First experiment was conducted in a cloudy day, and the result is shown in Figure 5. Red lines show temperature for ventilated hive, whereas gray lines show temperature for conventional hive. Different line style show different point of measurement as shown in the figure. It was found that temperature at all points started to rapidly increase around 11:00 until 12:00, then temperature constantly increased until in the end of the experiment. Temperature varies in the range of $27-31^{\circ} \mathrm{C}$, and this range is comfortable for bees. There is no significant difference in temperature between conventional and ventilated hive in all points. Thus, it can be concluded that the ventilated honey cassette does not improve thermal regulations under cloudy condition.

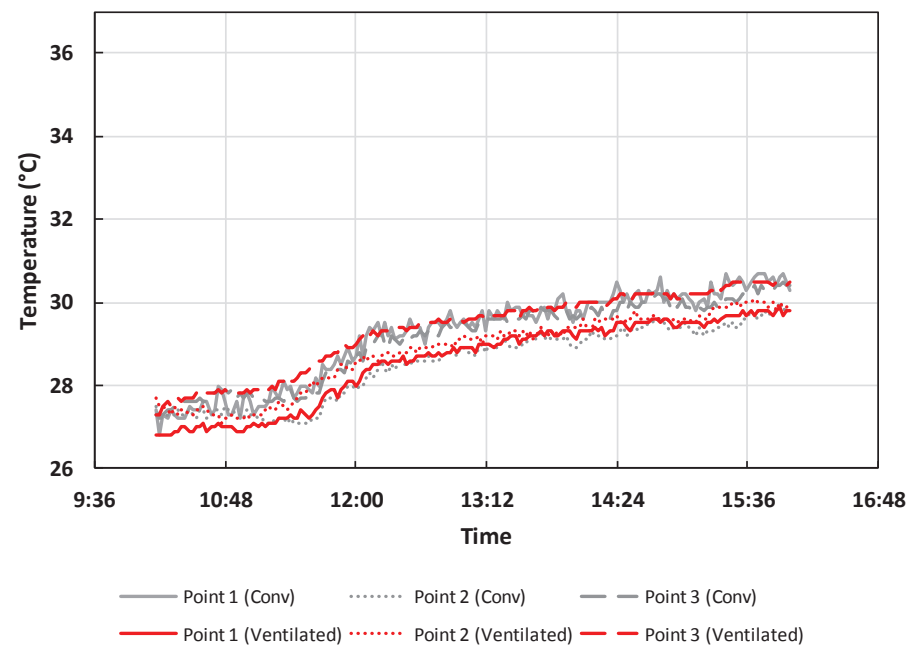

Fig. 5. Results of temperature for both hive in cloudy day. 
Experiment was repeated in sunny day, and the results is shown in Figure 6. It was found that the temperature for conventional hive is in the range of $32-36.5^{\circ} \mathrm{C}$, whereas temperature range for ventilated hive is lower and more stable in the range of $32.5-34.5^{\circ} \mathrm{C}$. If colony was alocated in the hive with the conventional honey cassette, pupae in the broodcell may die because the temperature is obviously above $34^{\circ} \mathrm{C}$.

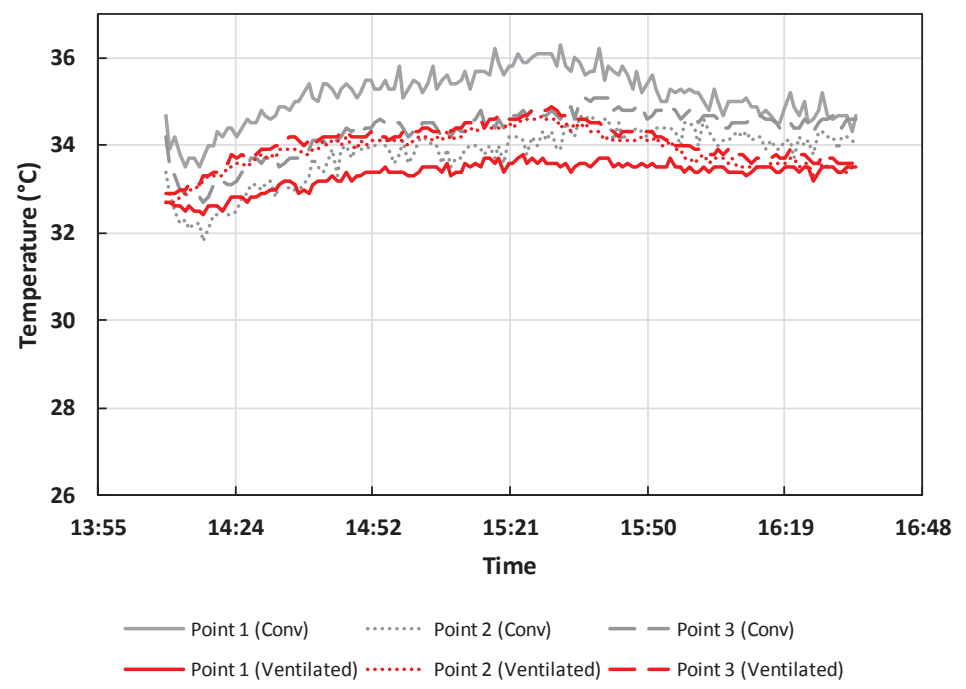

Fig. 6. Results of temperature for both hive in sunny day.

There are two significant improvements found in the hive with the ventilated honey cassette: (a) temperature at Point 1 for ventilated honey cassette was the lowest temperature, and it consistently below $33^{\circ} \mathrm{C}$, and this could help to avoid for the melting of propolis around the ventilated wall, (b) Better temperature drop started around 15:30 for the ventilated honey cassette as compared to the conventional honey cassette. These suggest that providing ventilation to the hive could reduce temperature around the wall of honey cassette, and further enhance cooling process inside the honey cassette. On top of that, the ventilated space could also help in drying honey in pots, and therefore fanning process for drying honey by bees could be reduced. In addition, combining a greenroof with the ventilated honey cassette will be the best option because temperature could be further reduced for $3.3-6.5^{\circ} \mathrm{C}$, on top of the existence of honey drying process by the ventilation. This could reduce the temperature inside hive to optimum temperature at $31-32^{\circ} \mathrm{C}$ as suggested by Fletcher et. al. However, further study when there is a colony inside the hives must also be conducted to validate the results.

\section{Conclusion}

Thermal performance of a ventilated honey cassette was tested and compared with a conventional honey cassette under direct sunlight. It was found that there is no significant difference between the hives when both hives were exposed under direct sunlight in a cloudy day. However, two significant improvement were found for ventilated hive in sunny day.

1) It could help to reduce temperature at wall of honey cassette consistently below $33^{\circ} \mathrm{C}$. This could avoid the melting of propolis around the ventilated wall area.

2) It could facilitates in better temperature reduction as compared to the conventional honey cassette. 
However, further study when there is a colony inside the hives must also be conducted to validate the results.

\section{References}

1. Schwarz, F., The Indo-Malayan Species of Trigona, Am. Museum Nat. Hist. 76 (1939) 83-141.

2. Roubik, D. W., Stingless bee nesting biology, Apidologie 37 (2006) 124-143.

3. Vollet-Neto, A., Menezes, C., and Imperatriz-Fonseca, V. L., Behavioural and developmental responses of a stingless bee (Scaptotrigona depilis) to nest overheating, Apidologie 46 (2015) 455-464.

4. Fletcher, D. J. C., and Crewe, R. M., Nest structure and thermoregulation in the stingless bee, Trigona denoiti, Hymenoptera: Apidae, J. Entomol. Soc. South Africa 44 (1981) 183-196.

5. Sung, I. H., Yamane, S., and Hozumi, S., Thermal characteristics of nests of the Taiwanese stingless bee Trigona ventralis hoozana (Hymenoptera: Apidae), Zool. Stud. 47 (2008) 417-428. 